\title{
INF- $\gamma$ encoding plasmid administration triggers bone loss and disrupts bone marrow microenvironment
}

\author{
Dimitrios Agas', Guilherme Gusmão Silva², Fulvio Laus', Andrea Marchegiani1, \\ Melania Capitani', Cecilia Vullo', Giuseppe Catone', Giovanna Lacava', \\ Antonio Concetti', Luigi Marchetti' and Maria Giovanna Sabbieti \\ ${ }^{1}$ School of Bioscience and Veterinary Medicine, University of Camerino, Camerino, Italy \\ 2Departamento de Bioquímica e Imunologia, Universidade Federal de Minas Gerais, Belo Horizonte, \\ Minas Gerais, Brazi
}

Correspondence should be addressed to M G Sabbieti Email giovanna.sabbieti@unicam.it

\begin{abstract}
IFN- $\gamma$ is a pleotropic cytokine produced in the bone microenvironment. Although IFN- $\gamma$ is known to play a critical role on bone remodeling, its function is not fully elucidated. Consistently, outcomes on the effects of IFN- $\gamma$ recombinant protein on bone loss are contradictory among reports. In our work we explored, for the first time, the role of IFN- $\gamma$ encoding plasmid ( $\mathrm{pIFN}-\gamma$ ) in a mouse model of osteopenia induced by ovariectomy and in the sham-operated counterpart to estimate its effects in skeletal homeostasis. Ovariectomy produced a dramatic decrease of bone mineral density (BMD). pINF- $\gamma$ injected mice showed a pathologic bone and bone marrow phenotype; the disrupted cortical and trabecular bone microarchitecture was accompanied by an increased release of pro-inflammatory cytokine by bone marrow cells. Moreover, mesenchymal stem cells' (MSCs) commitment to osteoblast was found impaired, as evidenced by the decline of osterix-positive $\left(\mathrm{Osx}^{+}\right)$cells within the mid-diaphyseal area of femurs. For instance, a reduction and redistribution of CXCL12 cells have been found, in accordance with bone marrow morphological alterations. As similar effects were observed both in shamoperated and in ovariectomized mice, our studies proved that an increased IFN- $\gamma$ synthesis in bone marrow might be sufficient to induce inflammatory and catabolic responses even in the absence of pathologic predisposing substrates. In addition, the obtained data might raise questions about pIFN- $\gamma$ 's safety when it is used as vaccine adjuvant.
\end{abstract}

Journal of Endocrinology (2017) 232, 309-321

\section{Introduction}

IFN- $\gamma$ is a potent immunomodulatory cytokine produced by a variety of leukocyte populations, which exerts multiple biological effects on a range of cell types. INF- $\gamma$ is either an osteo-anabolic or osteo-destructive cytokine, and its dual effect depends on experimental and clinical conditions.
Key Words
- INF- $\gamma$
- bone loss
- bone marrow
- plasmid DNA 
Persistent IFN- $\gamma$ signaling, occurring in chronic inflammatory states, was also associated to impaired hematopoietic stem cells (HSC) self-renewal (de Bruin et al. 2013), and high long-lasting IFN- $\gamma$ levels resulted in progressive multi-organ inflammation (Reinhardt et al. 2015).

Conversely, other reports attributed to IFN- $\gamma$ antiosteoclastogenic properties. Indeed, it was found that IFN- $\gamma$, by interfering with RANKL/RANK signaling, decreases NF- $\mathrm{BB}$ and cathepsin $\mathrm{K}$ expression in differentiating osteoclasts (Takayanagi et al. 2000, Pang et al. 2005). In addition, it was evidenced that IFN- $\gamma$ receptor-null mice showed reduced bone mineral density and impaired osteoblastogenesis (Duque et al. 2009). Noteworthy, exogenous administration of IFN- $\gamma$ to sham-operated (SO) and ovariectomized (OVX) mice (i) significantly increases the ratio between bone formation and bone resorption in SO mice and (ii) rescues osteoporosis in OVX mice (Duque et al. 2011). Consistently, intraperitoneal administration of INF- $\gamma$ reduces adipogenesis in vitro and favors hematopoiesis in OVX mice (Vidal et al. 2012). Furthermore, it has been demonstrated that IFN- $\gamma$ suppressed tumor-induced bone loss suggesting a protective role for IFN- $\gamma$ in patients with bone metastases (Xu et al. 2009).

To the author's knowledge, a large number (if not all) of approaches designed to test the activity of INF- $\gamma$ on bone has been conducted by administering INF- $\gamma$ recombinant proteins, in general needed in high supraphysiological doses and with possible consequent side effects; instead, information regarding the effects of the INF- $\gamma$ DNA delivery is not currently available. Indeed, it is well known that, unlike recombinant protein-based therapy, the gene could be efficient also at low doses and for extended periods (Evans 2010). Accordingly, the biological activities of important factors affecting bone remodeling such as bone morphogenetic proteins (BMPs) (Evans 2010), parathyroid hormone (PTH) (Fang et al. 1996) or osteogenic transcription factors (Zhao et al. 2007) were also tested by using various gene transfer approaches.

As the activation of INF- $\gamma$ signaling, by INF- $\gamma$ recombinant protein, has been proven not only to induce bone loss but has also been reported to protect against bone loss; in the present study, we evaluate the effects of IFN- $\gamma$ encoding plasmid in healthy and osteopenic mice to investigate whether this alternative method of IFN- $\gamma$ administration could be considered for therapeutic approaches.
Noteworthy, previous evidence showed the safety of plasmids encoding INF- $\gamma$ when used as adjuvant and/or to contrast cancer progression (Ishii et al. 1999, Ehtesham et al. 2002).

\section{Materials and methods}

\section{DNA plasmid}

pSV2neo IFN- $\gamma$ (pIFN- $\gamma$ ) plasmid was purchased from Addgene (Cambridge, MA, USA). IFN- $\gamma$ ORF deleted pSV2neo plasmid served as vector control. Large-scale preparation of plasmids was carried out using EndoFree Plasmid Mega Kit (Qiagen).

\section{Animals}

Female Balb-c mice (Harlan Italy SrL, Correzzana, Milano, Italy) were used. Mice were kept in laminar-flow cage in a standardized environmental condition. Food (Harlan, Italy) and water were supplied ad libitum. All animal-related procedures described were conducted in accordance with the recommendation of the Italian Ethical Committee. Anesthesia, surgical procedures, X-ray and killing were performed by accredited veterinarian physician involved in these studies.

\section{In vivo evaluation of the effects of pIFN- $\gamma$ on bone and bone marrow}

Mice ( 9 weeks old) were randomized into three groups, namely unoperated (naïve, $n=18$ ), sham-operated (SO, $n=18$ ) and ovariectomized to induce osteopenia (OVX, $n=18$ ). After 8 weeks, each group of mice was further divided into three subgroups. The subgroups were intramuscularly (i.m.) injected into the hind limb one time per week for 3 weeks as follows: one subgroup of mice $(n=6)$ received $100 \mu \mathrm{g}$ of IFN- $\gamma$ DNA in saline; the second subgroup of mice $(n=6)$ received $100 \mu \mathrm{g}$ pSV2 neo in saline; the third subgroup of mice $(n=6)$ received only saline. 2 months after the last injection, all mice were anesthetized with isoflurane-air mixture to perform X-ray analysis (as better described below). Immediately before killing, all mice were anesthetized and blood samples were collected, by cardiac puncture, to measure the level of seric cytokines. Then, all animals were killed by $\mathrm{CO}_{2}$ narcosis.

Published by Bioscientifica Ltd 


\section{$\mathrm{ROI}$ and quantitative X-ray analysis}

Anesthetized mice were positioned in dorsal recumbence, making sure that pelvis, femurs and tibias were included in radiographs. A portable X-ray generator (Gierth HF 80/15 plus ULTRA LEICH, Gierth X-Ray International GmbH, Riesa, Germany) mounted on a stative with focal distance of $60 \mathrm{~cm}$ was used; X-ray applied dose was $54 \mathrm{kV}$ for a time of $0.04 \mathrm{~s}$. Radiographs were acquired in DICOM format with Fujifilm FCR Capsule X (Fujifilm Corporation, Japan) and processed both with OsiriX (Pixmeo SARL, Berna, Switzerland) and ImageJ (http://rsb.info.nih.gov/ij/) software, according to image analysis protocols previously reported (McManus \& Grill 2011, Waung et al. 2014). Bone mineral density (BMD) was evaluated on femurs, vertebrae and pelvis by OsiriX software. The areas selected and defined as the regions of interest (ROI) are the following: proximal and distal femoral epiphyses, fifth lumbar spine vertebra and first sacral spine vertebra $(5600 \mu \mathrm{m} \times 7100 \mu \mathrm{m})$; femoral diaphysis $(3500 \mu \mathrm{m} \times 2400 \mu \mathrm{m})$ and ilium $(3500 \mu \mathrm{m} \times 2400 \mu \mathrm{m})$.

Subsequently, the DICOM images were converted with ImageJ into TIFF images and a 16-interval pseudocolor scale was applied to the gray scale. This scale starts from black pixels (value of zero), and increasing gradations of mineralization density are represented in 16 equal intervals by a pseudo-color scheme to white pixels (value of 255). Hence, distribution of pixels in the same ROI, defined as previously described, was calculated and displayed as a histogram.

\section{Histological evaluation of tissues and immunofluorescence analyses}

Spleen, lungs, heart and liver were collected from the above groups of mice, immediately after killing. Tissues were fixed in $4 \%$ paraformaldehyde (PFA) diluted in PBS for $72 \mathrm{~h}$ at $4^{\circ} \mathrm{C}$ and, after dehydration, they were embedded with paraffin. Tissue sections, 5-10 $\mu \mathrm{m}$ thick, were obtained by a microtome (Leica Reichert-Jung 2040). They were finally stained with hematoxylin and eosin or with Gomori's trichrome stains.

Femurs, dissected from adhering tissues, were fixed in $4 \%$ PFA as previously described. Then, bones were washed in PBS and decalcified in 14\% EDTA solution (pH 7.1) at RT for 3 days under constant agitation and soaked in 30\% sucrose overnight. Samples were embedded with TissueTek OCT compound. Then, $12 \mu \mathrm{m}$ thick cross-sections of femurs were obtained by a rotatory $-30^{\circ} \mathrm{C}$ air-dried microtome cryostat (Ames Cryostat Miles). Sections were stained with toluidine blue staining. Digital-assisted bone image analysis was performed as previously described by Egan et al. (2012).

Osteoclasts were stained for TRAP activity using leukocyte acid phosphatase (TRAP) commercial kit (SigmaAldrich) according to the manufacturer's instructions. Quantification of TRAP-positive osteoclasts, determined on a $1.5 \mathrm{~mm}$ length of endocortical surface of proximal femur epiphysis (area $0.3 \times 0.3 \mathrm{~mm}^{2}$ ), was performed using NIH ImageJ as previously described by Shimizu and coworkers (Shimizu et al. 2012).

Other sections were stained with freshly prepared oil red $\mathrm{O}$ to analyze bone marrow adipocytes.

In addition, trichrome-stained sections were prepared to estimate the amount of myeloid and erythroid cell populations (Travlos 2006a). Using a 100× objective lens, a count of differentiated and late phase of differentiation myeloid and erythroid cells was performed on 300 cells in 16 samples in each experimental group. All images were captured by a Leica DM 2500 light microscope.

For immunofluorescence analyses, other femur sections, after permeabilization with $0.3 \%$ Triton X-100, were incubated with rabbit anti-Osterix (Santa Cruz Biotechnology, DBA) diluted 1:50 or with rabbit antiCXCL12 (Abcam; Prodotti Gianni, Milano, Italy) diluted 1:80 in PBS at rt. After rinsing, sections were incubated with chicken anti-rabbit IgG Alexa Fluor 488 conjugated (Molecular Probes; Invitrogen) diluted 1:100 in PBS at rt. Control experiments were performed by omitting the appropriate primary antibodies or by neutralizing the primary antibodies with the relative blocking peptide. Slides were imaged using a Leica DM 2500 epifluorescence microscope.

\section{Total bone marrow cell (BMCs) and bone marrow stromal cell (BMSCs) preparation and cultures}

Long bones (femurs, tibiae and humeri) from the previously mentioned mice groups were dissected free of adhering tissues. Epiphyses were removed, and the marrow cavity was flushed. Total bone marrow cells (BMCs) were cultured for 2 days in DMEM plus $10 \%$ heat-inactivated-fetal calf serum (HIFCS), penicillin and streptomycin (Invitrogen). Then, culture medium and cells were collected to study the release of cytokines and chemokines, both in the supernatant and in the cells. Other BMC cells from the same mice groups were maintained in culture for 10 days to generate monolayers of adherent cells (Bianco et al. 2013), referred as bone marrow stromal cells (BMSCs).

Published by Bioscientifica Ltd 


\section{Cytokines and chemokines assay}

The cytokine/chemokine profiles in supernatants of 2-day cultured BMCs population as well as in serum samples were assessed by using Mouse Cytokine Array Panel A kit (R\&D Systems) according to the manufacturer's instructions. Immunoreactive dots were visualized using LiteAblot Turbo luminol reagents (EuroClone, Milano, Italy) and Hyperfilm-ECL film (EuroClone) and quantitated densitometrically.

\section{Real-time PCR for osteocalcin (Ocn), osteopontin (Opn) and INF- $\gamma$}

Total RNA was extracted in TRIzol reagent (Invitrogen) from mice and BMCs. cDNA was synthesized using RevertAid H Minus First Strand cDNA Synthesis Kit (Fermentas, Thermo Fisher) according to manufacturer's protocol. PCR primers are listed here: mouse Ocn Fw. 5'-TCT GAC CTC ACA GAT GCC AAG CCC-3' and mouse Ocn Rev. 5'-TAG GCG GTC TTC AAG CCA TAC TGG-3'; mouse Opn Fw. 5'-TCC CGG TGA AAG TGA CTG ATT CTG G-3' and mouse Opn Rev. 5'-TGG CTT TCA TTG GAA TTG CTT GGA AGA G-3'; mouse IFN $\gamma$ Fw. 5'-TAT TTT AAC TCA AGT GGC ATA GAT GTG G-3' and mouse IFN $\gamma$ Rev. 5'-TGA CAT GAA AAT CCT GCA GAG CCA G-3'; mouse $\beta$-actin Fw. 5'-GGCTGTATTCCCCTCCATCG-3' and mouse $\beta$-actin Rev. 5'-CCAGTTGGTAACAATGCCATGT-3'.

Real-time PCR was performed in three replicates of each sample using DyNAmo Flash SYBR Green qPCR Kit (Thermo Fisher) on a Stratagene Mx3000P; each reaction tube contained a total of $50 \mathrm{ng}$ cDNA into $20 \mu \mathrm{L}$ total reaction volume. The housekeeping gene actin was used as internal control to normalize the amount of target cDNA added to the reactions. Data are expressed as fold change of gene expression relative to empty vector injected mice.

\section{Western blotting}

Proteins from total BMCs and from BMSCs were extracted in cell lysis buffer (Cell Signaling, EuroClone) after 2 days of culture, and the concentration was determined by the BCA protein assay reagent (Pierce, EuroClone). Western blotting was performed as previously described (Sabbieti et al. 2010). Membranes were immunoblotted in blocking buffer with specific antibodies: rabbit anti-TNFo and rabbit anti-NF-кB (BioLegend, Microtech SrL, Napoli, Italy) both diluted 1:500; mouse anti-RANKL, rabbit antiTRAF6, rabbit anti-CXCL12 and rabbit anti-TGF (Abcam,
Prodotti Gianni) all diluted 1:600; rabbit anti-PPR $\gamma$ (Santa Cruz Biotechnology, Inc. DBA) diluted 1:300 and rabbit anti-Osterix (Santa Cruz Biotechnology, DBA) diluted 1:300. After washing with PBS-T, blots were incubated with horseradish peroxidase (HRP)-conjugated donkey anti-rabbit IgG or with HRP-conjugated rabbit anti-mouse IgG (Cell Signaling, EuroClone) both diluted 1:50,000. Immunoreactive bands were visualized using LiteAblot Turbo luminol reagents (EuroClone) and HyperfilmECL film (EuroClone) according to the manufacturer's instructions. To normalize the bands, filters were stripped and re-probed with a monoclonal anti- $\alpha$-tubulin (SigmaAldrich). Band density was quantified densitometrically.

\section{Statistical analysis}

All in vitro and in vivo data were expressed as a mean \pm standard error (s.E.). Two-way analysis of variance (ANOVA) was used to compare the variables induced by ovariectomy and treatments with the vector control (pSV2neo) and with pIFN- $\gamma$. Turkey test was used in multiple comparisons among all groups. All the statistical analyses were performed using the GraphPad Prism (v 6.01) on a personal computer O.S. Windows 10. Data were presented as mean \pm s.E. Values of $P<0.05$ were considered significant.

\section{Results}

\section{INF- $\gamma$ encoding plasmid induces bone disruption}

Ovariectomy was used to obtain an osteopenic mouse model, and the efficacy of this procedure was confirmed by the drastic reduction of bone mineral density (BMD) in OVX mice when compared with their SO controls, as assessed by X-ray analysis (proximal femoral epiphysis: $-24.01 \%, P<0.0001$ vs SHAM; distal femoral epiphysis: $-40.19 \%, P<0.0001$ vs SHAM; femoral diaphysis: $-19.23 \%, P<0.0003$ ) (Fig. $1 \mathrm{~A}$ and $\mathrm{B}$ ).

Administration of pIFN- $\gamma$ by intramuscular injection to SO mice decreased BMD especially in femurs and also in lumbar and sacral vertebrae and in ilia. In addition, pINF- $\gamma$ further aggravated bone resorption in the OVX group as demonstrated by the decrease of BMD overall evident at femoral level (Figs 1A, C, 2 and Table 1), and no significant ovariectomy $\times$ treatment interaction was found indicating that the responses to pIFN- $\gamma$ were not associated with ovarian status. 
As overlapping results were obtained in naïve and in SO mice as well as by saline and by pSV2 neo treatments, we omitted data related to naïve and to saline-treated mice (third subgroup) to avoid unnecessary repetitions.

In accordance with the X-ray data, histological analyses of femurs from pINF- $\gamma$-treated mice revealed a clear osteopenic phenotype characterized by loss of trabecular microarchitecture (Fig. 3A) and increased cortical porosity (Fig. 3C). In particular, the SO group of mice treated with pINFy showed bone volume fraction (BV/TV) significantly reduced and similar to the BV/TV of OVX mice. Moreover, the OVX-pINFy treated group presented a BV/TV significantly lower in comparison with the other groups analyzed, and no significant
A

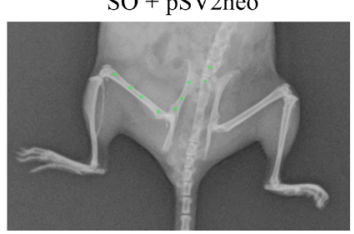

B

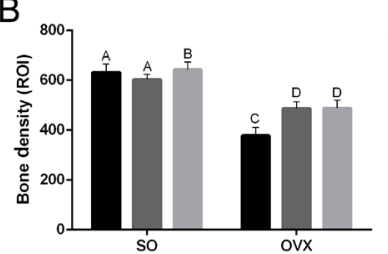

C

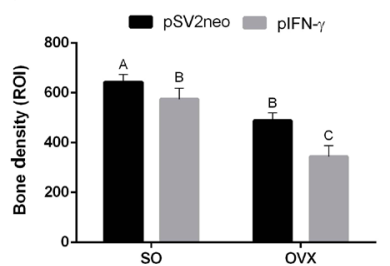

Proximal epiphysis

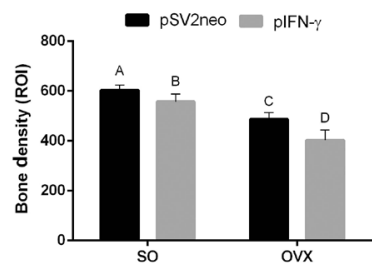

Diaphysis

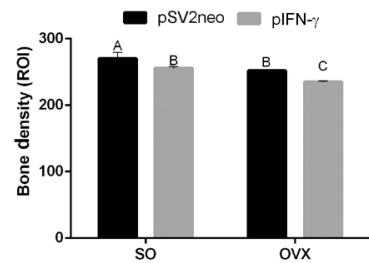

$1^{\text {st }}$ sacral vertebra
$\mathrm{SO}+\mathrm{pIFN}-\gamma$

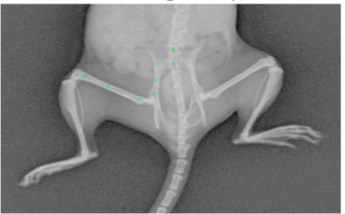

$\mathrm{OVX}+\mathrm{pIFN}-\gamma$
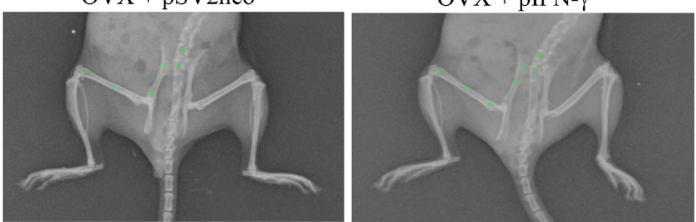
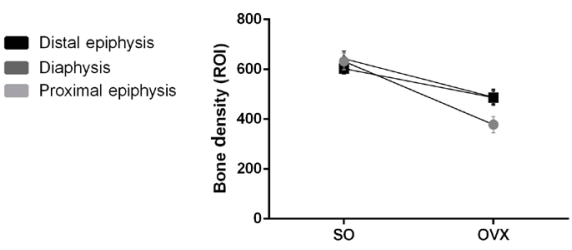

- Diaphysis

$\rightarrow$ Distal epiphysis

- Proximal epiphysis

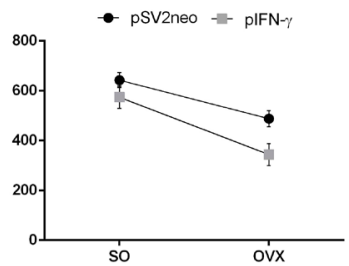

Proximal epiphysis

- pSV2neo - - pIFN-y

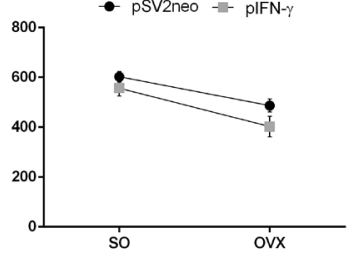

Diaphysis

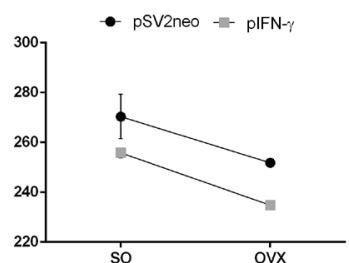

$1^{\text {st }}$ sacral vertebra

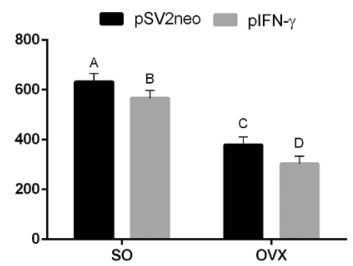

Distal epiphysis

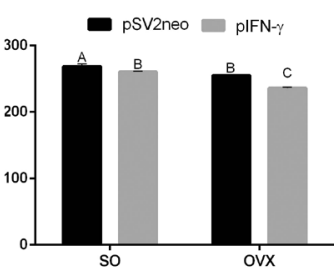

$5^{\text {th }}$ lumbar vertebra

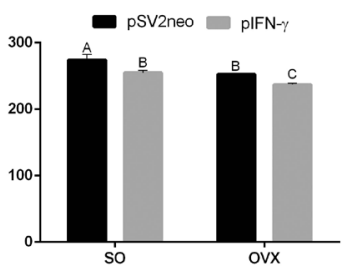

Ilium

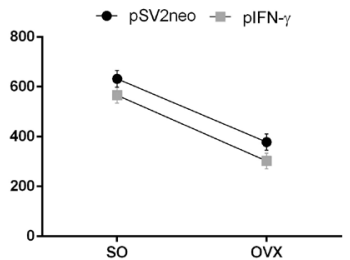

Distal epiphysis

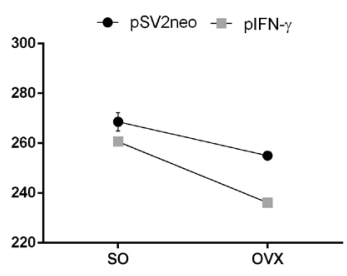

$5^{\text {th }}$ lumbar vertebra

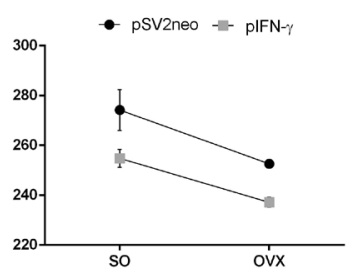

Ilium

Figure 1

X-ray images of lumbar and sacral vertebrae, pelvis and hind limbs of mice ( $n=6$ mice per group). Regions of interest (ROI) are represented as green ellipsoids (A). Histogram and plot of BMD at femoral proximal and distal epiphyses, femoral diaphysis, in mice SO or OVX from the original 16-bit DICOM X-ray radiographs Two-way ANOVA shows the statistically significant effects of ovariectomy, with no statistically significant interaction between the variables $(B): P<0.05$. Histograms and plots of BMD at femoral proximal and distal epiphyses, femoral diaphysis, 5 th lumbar and the 1 st sacral vertebra and ilium in mice SO or OVX treated with vector control or with pINF $\gamma$ from the original 16-bit DICOM X-ray radiographs. Two-way ANOVA shows the statistically significant effects of ovariectomy and pINF $\gamma$, with no statistically significant interaction between the variables $(C) ; P<0.05$.

http://joe.endocrinology-journals.org DOI: $10.1530 / J O E-16-0538$ (c) 2017 Society for Endocrinology Printed in Great Britain
Published by Bioscientifica Ltd 

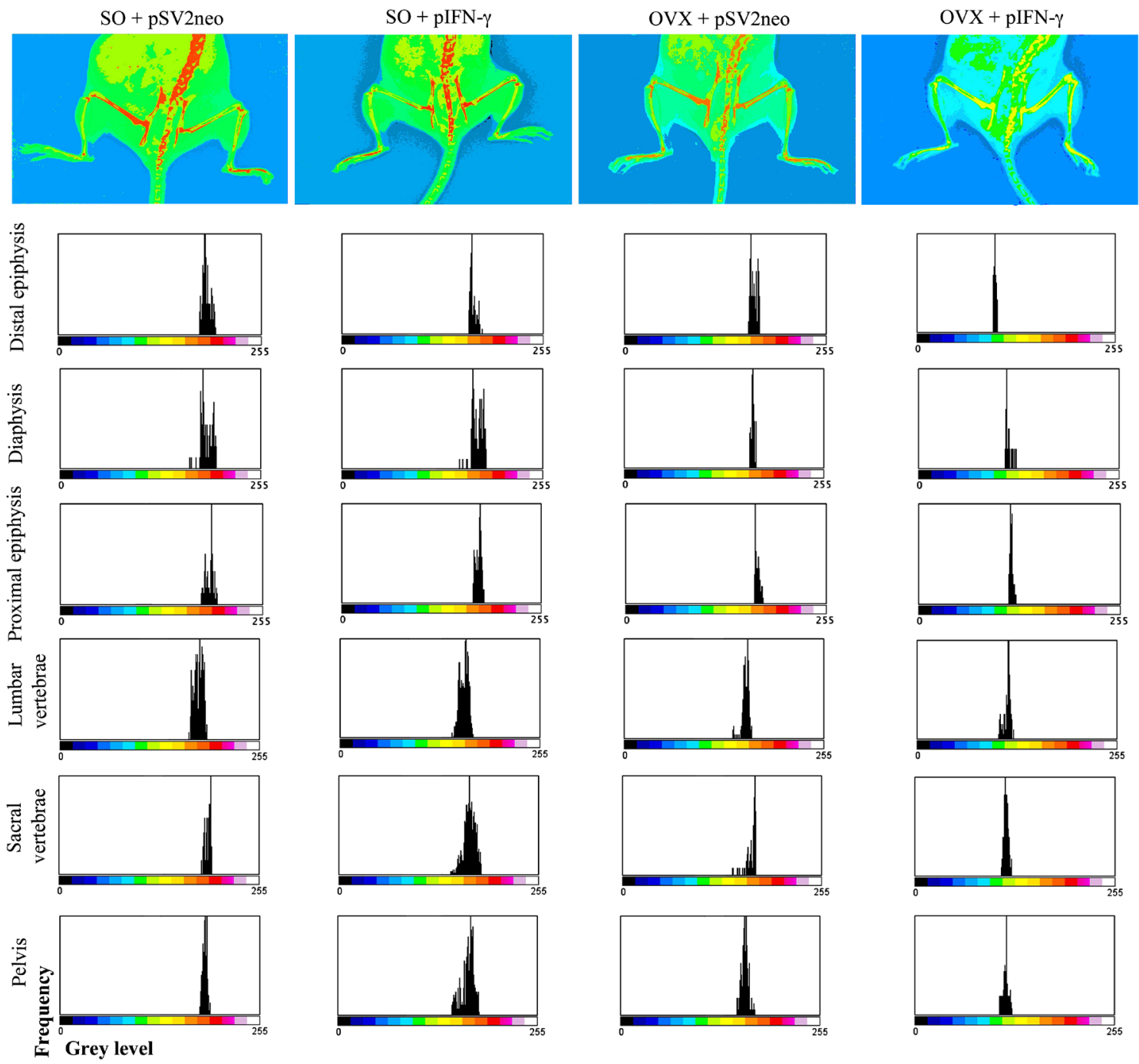

Figure 2

Pseudo-color images of pelvis and hind limbs of the X-ray images represented in Fig. 1, obtained converting to an 8-bit TIFF format from the original 16-bit DICOM X-ray radiographs and pseudo-coloring the resultant image using a 16 color look-up table. In pseudo-color images, lower mineral bone content is green and yellow and higher bone mineral content is red and purple. Histogram of gray levels frequency within subchondral bone ROI.

ovariectomy $\times$ treatment interaction was observed (Fig. 3B). Staining of femurs with TRAP revealed that pINF- $\gamma$ consistently increased trabecular bone disruption especially in OVX mice, in which the osteolytic lesions, particularly evident within the epiphyseal trabecular network, occupied larger areas in respect to those in the OVX-untreated group (Fig. 3D and E).

Furthermore, an increased fatty marrow, evidenced by oil red staining, was observed in pINF $\gamma$-treated groups mainly concentrated in the sub-metaphyseal region (Fig. 3F and G) and less in the mid-diaphyseal area.

The bone erosions found in both pINF- $\gamma$-injected OVX and SO mice were accompanied with an increased synthesis and release of inflammatory/osteoclastogenic molecules. Indeed, Western blotting analysis of whole
BMCs lysates showed an upregulation of $\mathrm{TNF} \alpha, \mathrm{NF} \kappa \mathrm{B}$, TRAF6 and RANKL (Fig. 3H); furthermore, analysis of BMC supernatants evidenced an enhanced secretion of proinflammatory cytokines/chemokines in treated groups. In addition, by two-way ANOVA, a significant interaction was evidenced for the production of certain cytokines and chemokines such as IL-10, IL-17, IL-27, G-CSF, CXCL12 and IL-1ra (Fig. 4).

Conversely, no statistically significant differences among groups were observed regarding serum level of INF- $\gamma$ or other cytokines at least at the time of samples collection (2 months after the last treatment) (data not shown). In addition, histopathological alterations were not observed in various organs examined (data not shown) indicating that the harmful effects of pINF- $\gamma$ administration were

Published by Bioscientifica Ltd 
Table 1 Effects of pINF $\gamma$ on BMD in SO and OVX mice expressed as mean percent difference between SO-pINF $\gamma$ treated and SO-pSV2neo-treated mice and between OVXpINF $\gamma$-treated and OVX-pSV2neo-treated mice ( $n=6$ mice per group) (D); $P<0.05$.

\begin{tabular}{|c|c|c|}
\hline & SO + pINF $\gamma$ & $O V X+p I N F \gamma$ \\
\hline $\begin{array}{l}\text { Proximal } \\
\text { femoral } \\
\text { epiphysis }\end{array}$ & $-6.06(-18.71,-4.46)$ & $-29.51(-43.47,-19.52)$ \\
\hline $\begin{array}{l}\text { Distal } \\
\text { femoral } \\
\text { epiphysis }\end{array}$ & $-10.44(-11.17,-9.89)$ & $-20.10(-24.77,-17.14)$ \\
\hline $\begin{array}{l}\text { Femoral } \\
\text { diaphysis }\end{array}$ & $-7.63(-13.08,-3.08)$ & $-17.25(-29.29,-8.13)$ \\
\hline $\begin{array}{l}5 \text { th lumbar } \\
\text { vertebra }\end{array}$ & $-2.98(-0.08,-5.68)$ & $-7.37(-7.42,-7.33)$ \\
\hline $\begin{array}{l}\text { 1th sacral } \\
\text { vertebra }\end{array}$ & $-5.4(1.34,-11.08)$ & $-6.75(-6.88,-6.76)$ \\
\hline Ilium & $-7.07(-3,-10.56)$ & $-6.1(-6.56,-5.64)$ \\
\hline
\end{tabular}

Mean percent difference $=\left(\mathrm{pINF} \gamma_{\text {mean }}-\mathrm{pSV} 2\right.$ neo $\left._{\text {mean }}\right) / \mathrm{pSV} 2$ neo $_{\text {mean }} \times 100$.

likely limited to bone and to bone marrow. These data support previous studies, which defined the bone marrow compartment as a partially autonomous environment strategic for evaluating the levels of cytokines that target bone (Harsløf et al. 2013).

\section{Mesenchymal stem cells' (MSCs) fate to osteoblasts is negatively influenced by pINF- $\gamma$}

Next, in BMSCs, we examined whether pINF- $\gamma$ affected the synthesis of Osx, which are required for MSCs commitment to osteoblasts, and PPAR $\gamma$ that favors differentiation of MSCs into adipocytes. A dramatic decrease of Osx along with an increase of PPAR $\gamma$ (Fig. 5A) was evidenced in BMSCs from pINF- $\gamma$-treated mice groups. Consistently, immunohistochemical analyses evidenced a decrease of $\mathrm{Osx}^{+}$cells especially in the sub-metaphyseal femoral region (Fig. 5B).

In addition, RT-PCR on BMSCs showed that pINF- $\gamma$ downregulated the expression of osteocalcin, which is released by mature osteoblasts; on the other hand, the effector increased osteopontin, which is known both to inhibit bone mineralization (Gericke et al. 2005, Yuan et al. 2014) and to sustain inflammatory signals (Weber et al. 2002, Bruemmer et al. 2003) (Fig. 5C).

\section{INF- $\gamma$ decreases CXCL12+ cells and alters bone marrow morphology}

As showed in Fig. 2I, pINF- $\gamma$ decreased the release of CXC chemokine ligand 12 (CXCL12, also known as stromal derived factor 1 (SDF-1)) that plays critical roles both in maintaining bone marrow niche (Jung et al. 2006, Sugiyama et al. 2006) and in controlling HSCs homing in the bone marrow activity and self-renewal (Ehninger \& Trumpp 2011). Accordingly, Western blotting on BMSCs, that are the main providers of CXCL12 (Sugiyama et al. 2006, Agas et al. 2013), showed that the treatment downregulated this chemokine (Fig. 6A).

Furthermore, immunohistochemical analysis of femoral mid-diaphysis sections from pINF- $\gamma$-treated mice showed that CXCL12+ cells were decreased and were redistributed away from the perivascular areas (Fig. 6B). Together, this evidence suggested that pINF- $\gamma$ could provoke an alternate engraftment/homing of BMCs population. Furthermore, we detected, in BMSCs from pINF $\gamma$-treated mice, a decreased synthesis of TGF- $\beta$ which could be correlated with BMSCs niche disruption within the bone marrow confines (Fig. 6C).

Accordingly, histological analyses of femur middiaphysis from pINF- $\gamma$-injected mice evidenced bone marrow areas displaying flattened nutrient arteries and venous sinuses. Namely, we also observed bone marrow regions characterized by hypercellularity. In particular, an increment of both erythroid and myeloid cells was found in SO-pINF- $\gamma$-treated mice, whereas an increase of myeloid cells was detected in OVX-pINF- $\gamma$-treated group (Fig. 6D and E). Moreover, in SO-pINF- $\gamma$ treated mice, nutrient arteries (adjacent to hyperplastic areas) appeared extended and flattened; in addition, the collecting venules have thread-like appearance in OVX-treated mice (Fig. 6E). These data are in line with other reports claiming that inflammation alters the number and morphology of the sinus with parallel decrease of trabecular bone volume and (not in all cases) increase of adipose tissue (Burkhardt et al. 1987).

\section{Discussion}

In our research, we addressed to the impact of INF- $\gamma$ gene delivery on bone and bone marrow in osteopenic and healthy mice. The intramuscular route for injection of the INF- $\gamma$ DNA, in addition to be a minimally invasive procedure, was selected based on our previous studies. Indeed, we demonstrated that such way of delivering plasmid DNA markedly affects bone and bone marrow (Sabbieti et al. 2015, Agas et al. 2016), although elucidation of the mechanism is still under our investigation.
๑) 2017 Society for Endocrinology Printed in Great Britain 
A

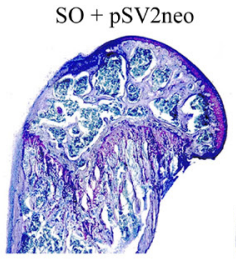

B

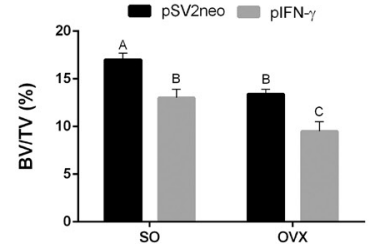

c

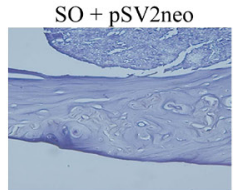

OVX + pSV2neo

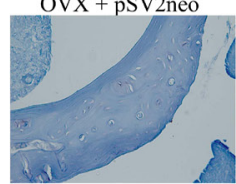

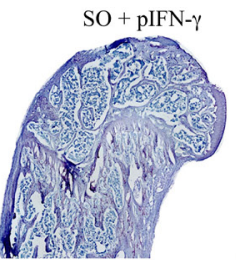
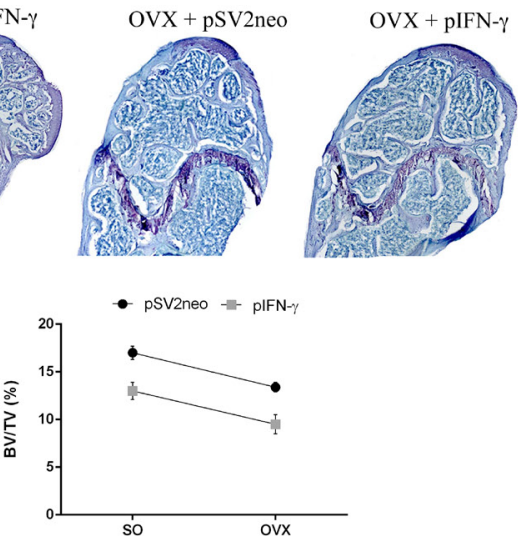

so
$\mathrm{SO}+\mathrm{pIFN}-{ }^{\prime}$

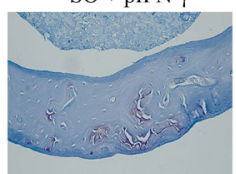

OVX + pIFN- -

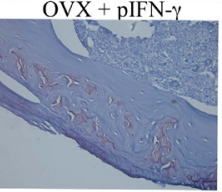

D $\quad \mathrm{SO}+\mathrm{pSV} 2 \mathrm{neo}$

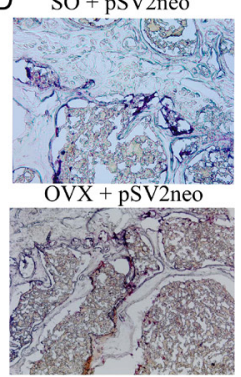

- pSV2neo - - plFN-

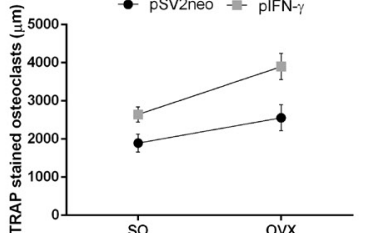

$\mathrm{SO}+$ pIFN- $\gamma$

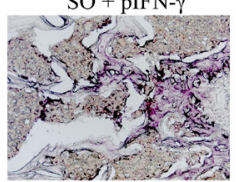

OVX + pIFN

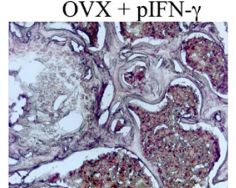

E

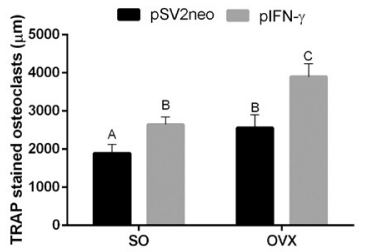

F $\quad \mathrm{SO}+$ pSV2neo

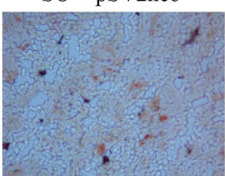

OVX + pSV2neo

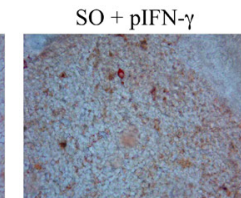

OVX + pIFN- $\gamma$

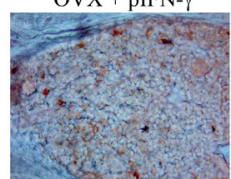

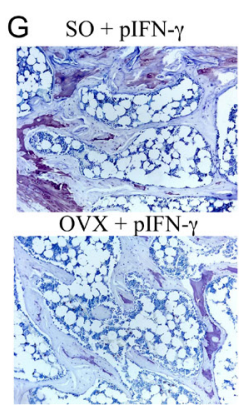

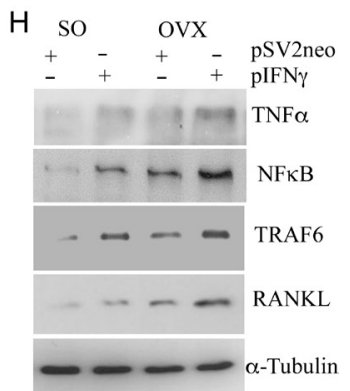

\section{Figure 3}

Representative reconstruction of epiphyseal and metaphyseal regions of proximal femurs from SO and OVX mice treated with the pSV2neo or with pINF- $\gamma$ DNA ( $n=6$ mice per group), stained with toluidine blue (A). Quantitative analysis of ratio of the bone volume (BV) to the total volume (TV) determined on a $1.5 \mathrm{~mm}$ length of endocortical surface of the proximal femur epiphysis measured using 12 sections from each sample. Images for quantitating tissue volume were taken at $20 \times$ magnification and standardized to be the same size. The representative histogram and plot illustrate averaged results; two-way ANOVA shows the statistically significant effects of ovariectomy and pINF $\gamma$, with no statistically significant interaction between the variables (B); $P<0.05$. Representative sections of femur mid-diaphysis from SO and OVX mice treated with the pSV2neo or with pINF- $\gamma$ DNA (C). Representative TRAP staining of osteoclasts at proximal femur epiphysis from SO mice and OVX mice treated with the plasmid control or with pINF- $\gamma$ ( $n=6$ mice per group). Magnifications: $20 \times(D)$. Quantification of TRAP-positive osteoclasts determined on a $1.5 \mathrm{~mm}$ length of endocortical surface of proximal femur epiphysis (area $0.3 \times 0.3 \mathrm{~mm}^{2}$ ). Statistical analysis derives from the examination of 12 sections from each sample; two-way ANOVA shows the statistically significant effects of ovariectomy and pINF $\gamma$, with no statistically significant interaction between the variables (E); $P<0.05$. Representative oil red staining of adipocytes at femur sub-metaphyseal regions from SO and OVX mice vector (pSV2neo) or pINF- $\gamma$ treated (F). Magnifications: 20x. Toluidine blue staining emphasizing areas enriched in adipocytes at femur sub-metaphyseal regions in pIFN- $\gamma$-treated groups. Magnifications: $20 \times(G)$. Representative Western blotting of TNF- $\alpha, N F \kappa B$, TRAF6 and RANKL of total bone marrow cells (BMCs) obtained by SO and OVX mice treated with only vector (pSV2neo) or with pINF- $\gamma(\mathrm{H})$. 


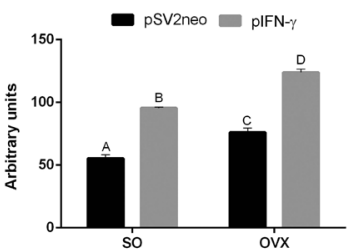

IL-1 $\alpha$

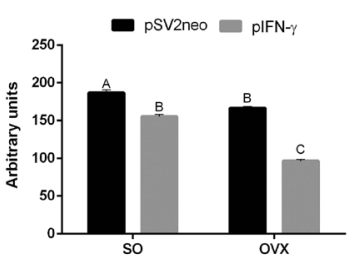

IL-1ra

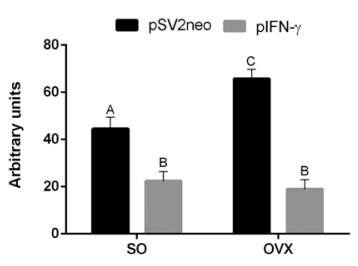

IL-10

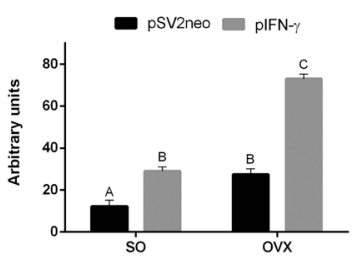

IL-27

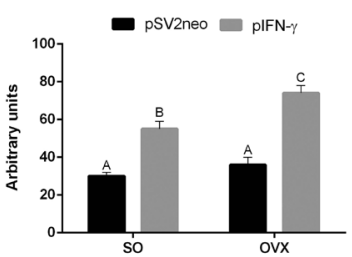

GM-CSF

pSV2neo pIFN-y

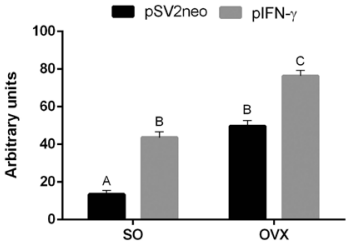

IFN- $\gamma$

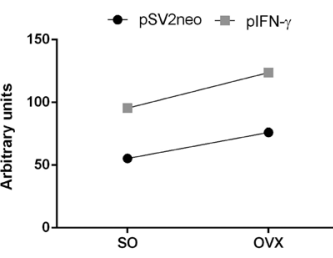

IL-1 $\alpha$

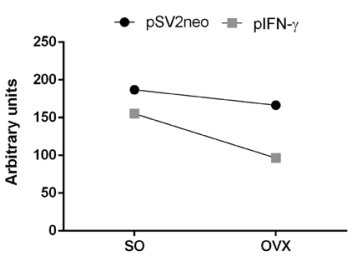

IL-1ra

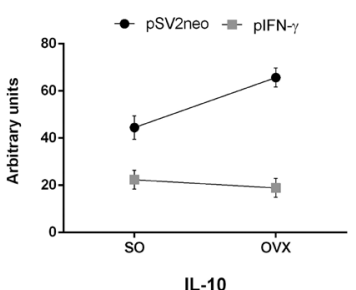

IL-10

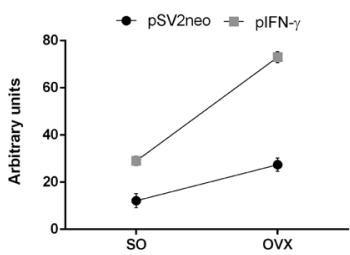

เL-27

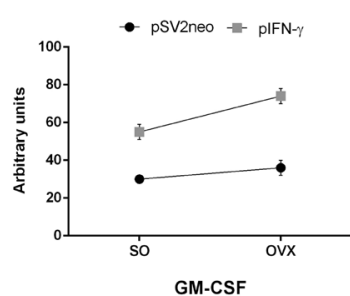

- pSV2neo - pIFN-

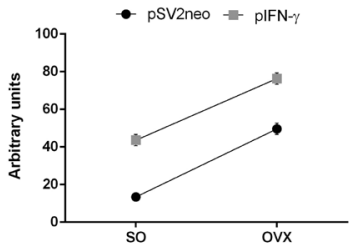

IFN- $\gamma$

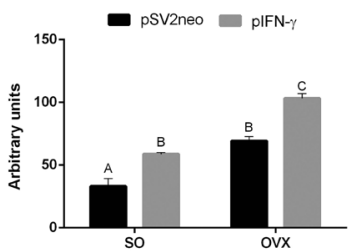

IL-1 $\beta$

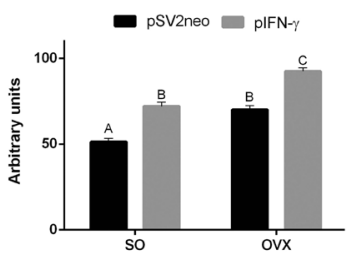

IL-6
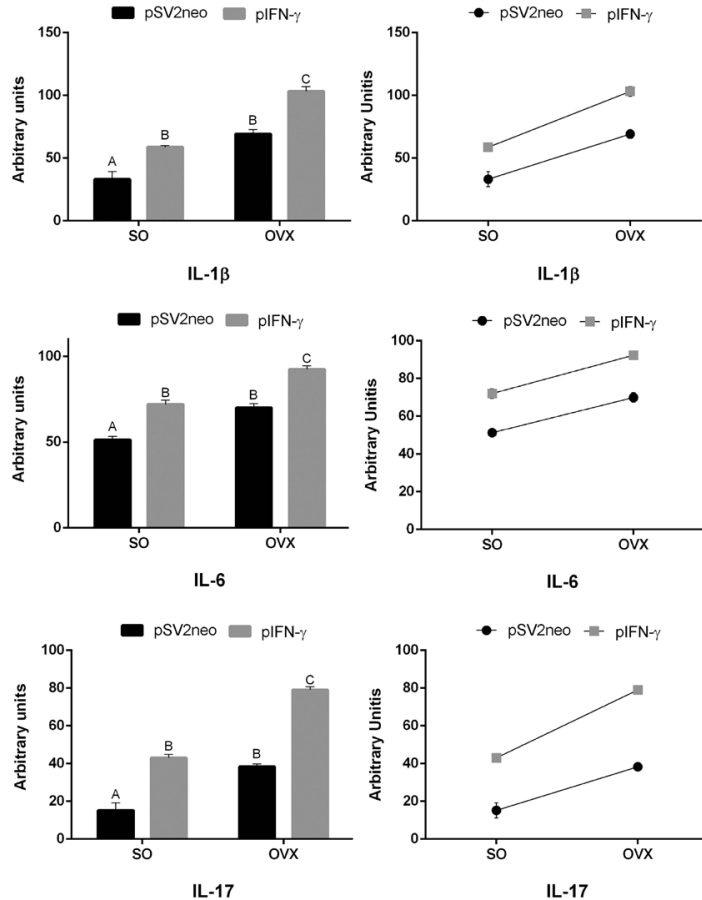

IL-1 $\beta$

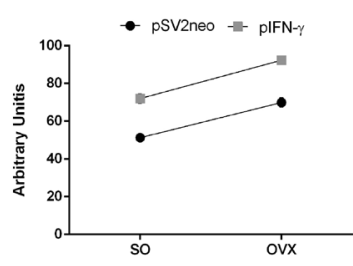

IL-6
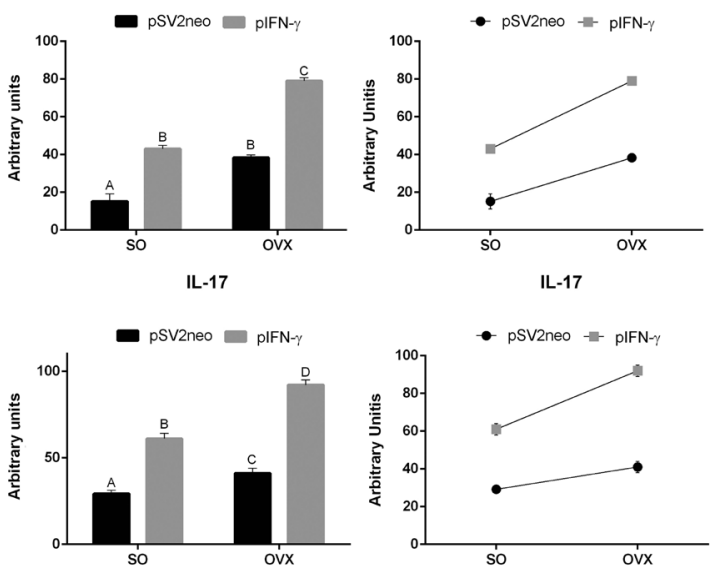

G-CSF
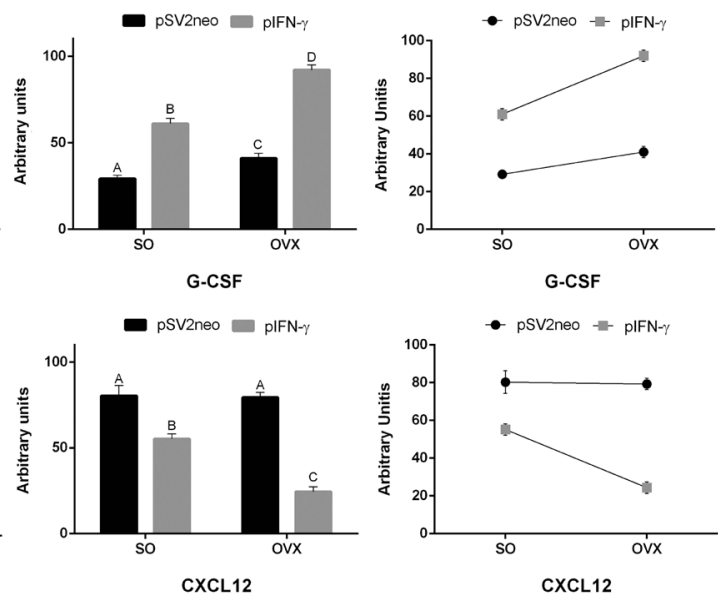

G-CSF

- pSVZneo - - pIFN-\%

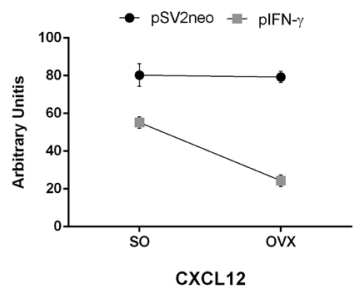

CXCL12

Figure 4

Histograms and plots of cytokines and chemokines release analyzed in medium from total bone marrow cell (BMCs) cultures obtained by SO and OVX mice pSV2neo or pINF- $\gamma$ treated ( $n=6$ mice per group). Two-way ANOVA shows the statistically significant effects of ovariectomy and pINF- $\gamma$ with no statistically significant interaction between the variables for IL-1 $\beta$, IL-6, GM-CSF and IFN- $\gamma$. Statistically significant interaction between the variables was found for IL-1ra, IL-10, IL-17, IL-27, G-CSF and CXCL12; $P<0.05$.

Our results reveal that treatment with INF- $\gamma$ DNA exacerbates bone loss, in OVX mice. Although the bone density was mainly decreased in femurs, a certain degree of osteopenia was also appreciated in vertebrae and pelvis, indicating that the effects of pINF- $\gamma$ on the skeleton were not site-specific. In addition, we found an increased release of inflammatory/osteoclastogenic cytokines by the bone marrow cells of OVX-pINF- $\gamma$ 
A

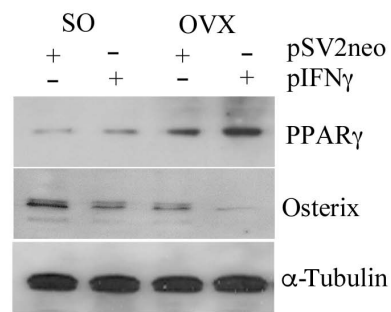

B
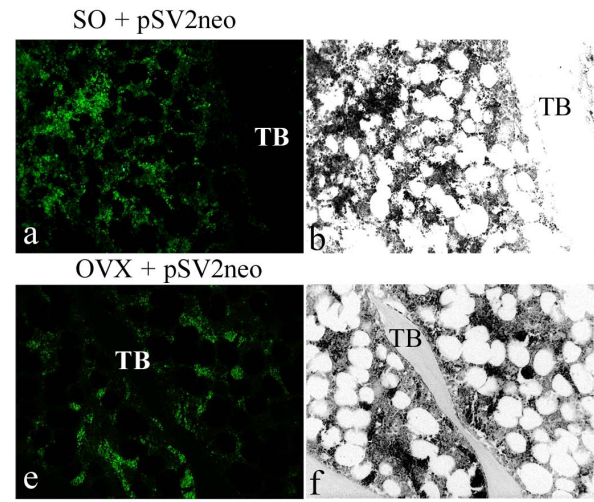
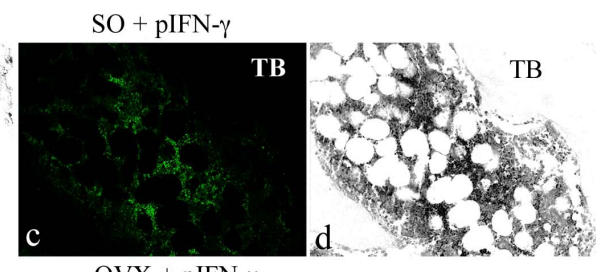

$\mathrm{OVX}+\mathrm{pIFN}-\gamma$
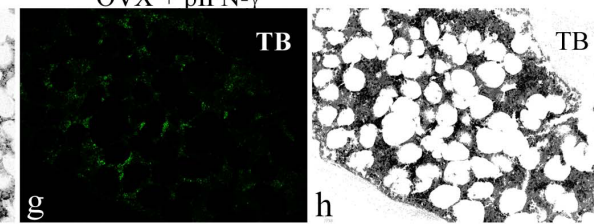

C

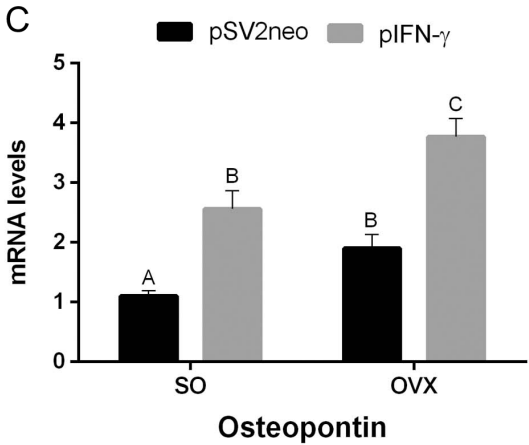

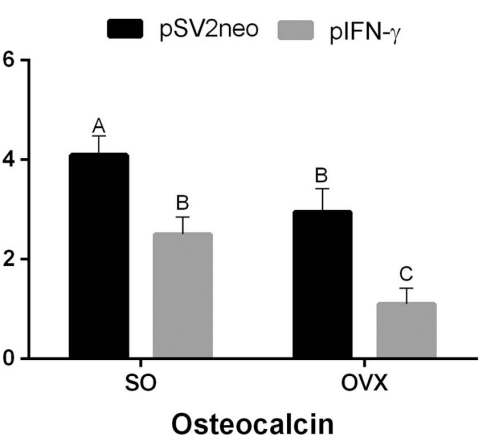

\section{Figure $\mathbf{5}$}

Representative Western blotting of PPAR $\gamma$ and OSX of BMSCS obtained by SO and OVX mice treated with pSV2neo or with pINF- $\gamma$ ( $n=6$ mice per group) (A). Localization of OSX at femur sub-metaphyseal areas from mice SO vector treated (Ba), OVX vector treated (Be), SO pINF- $\gamma$ (Bc) and OVX pINF- $\gamma(\mathrm{Bg})$, analyzed on 12 sections from each sample, by fluorescent microscope using the rabbit anti-OSX antibody (green: FITC staining).

Histological sections from the same regions are shown (Bb, Bd, Bf and Bh). (TB, trabecular bone). Magnifications: 20x. Gene expression of osteopontin and osteocalcin by real-time PCR of total RNA from bone marrow cells (BMSs) (C); $P<0.05$.

treated mice. In this regard, by two-way ANOVA, a significant ovariectomy $\times$ treatment interaction for the release of cytokines that play critical roles in bone loss such as IL-17 was observed (Moon et al. 2012). This result suggests that a synergistic effect of ovariectomy and pINF- $\gamma$ may worsen the osteopenic process in OVX mice. In support of this hypothesis, it was previously demonstrated that INF- $\gamma$ synergizes with TNF- $\alpha$ in inducing bone marrow MSCs apoptosis (Liu et al. 2011). In our study, we speculate that the augmented levels of INF- $\gamma$ could mediate and/or cooperate with pro-inflammatory signals that are known to be released after ovariectomy (Weitzmann \& Pacifici 2006). These inflammatory signals, in turn, could inhibit MSCs commitment into osteoblasts and, by this way, could aggravate the osteopenia in ovariectomized mice.

To assess the validity of our speculation, that inflammatory molecules produced by OVX mice could play a critical role in pINF- $\gamma$-induced osteopenia, we also tested the effects of pINF- $\gamma$ on SO healthy mice. Interestingly, we observed a dramatic bone resorption associated with an increased release of important inflammatory/osteoclastogenic cytokines by the bone marrow cells of pINF- $\gamma$-treated SO mice. Thus, estrogens failed to repress the pINF- $\gamma$ 'burning' signals. Indeed, levels of molecules such as interleukin-17 (IL-17) were similar in BMCs cultures of pINF- $\gamma$-treated SO and OVX mice. In particular, IL-17 stimulates the release of RANKL by osteoblasts and osteocytes and consequently potentiates the osteoclastogenic activity (Pacifici 2016). Moreover, it is well known that IL-1 and TNF, that were found increased both in SO and in OVX mice, intensify the bone resorption process (Pacifici 2016). Hence, these data suggest that IFN- $\gamma$ could enhance the osteoclastogenic IL-17/IL-1/TNF signaling network, amplifying their bone catabolic action. Consistently, the osteo-destruction was associated with an increased expression and release of INF- $\gamma$ (Supplementary Fig. 1, see section on supplementary data given at the end of this article). Thus, it is possible that the gene injection could be per se sufficient to build up a local inflammatory scenario.

Moreover, our data suggest that the osteopenia due to pINF- $\gamma$ and the bone resorption-induced estrogen depletion may occur through distinct pathways.

Published by Bioscientifica Ltd 
A

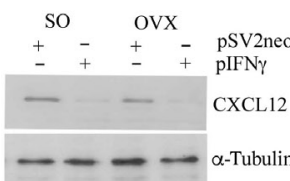

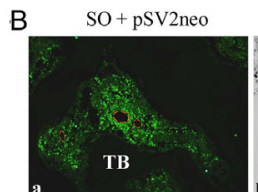

OVX + pSV2neo

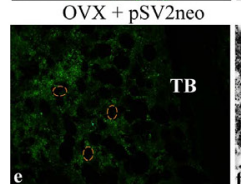

TB
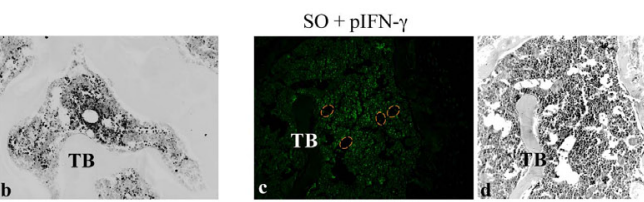

C
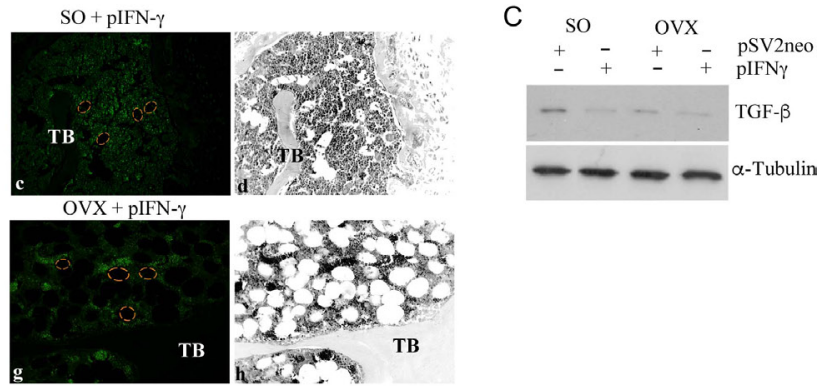

D

$\mathrm{SO}+$ pSV2neo

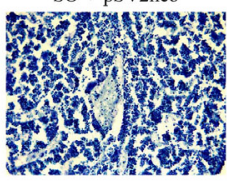

$\mathrm{SO}+\mathrm{pIFN}-\gamma$
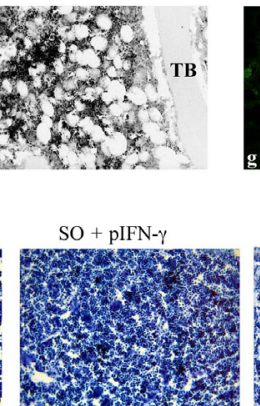

OVX + pSV2neo

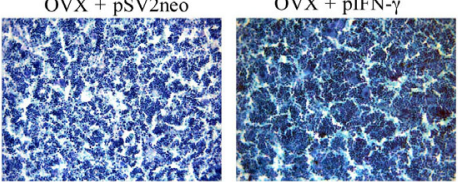

E
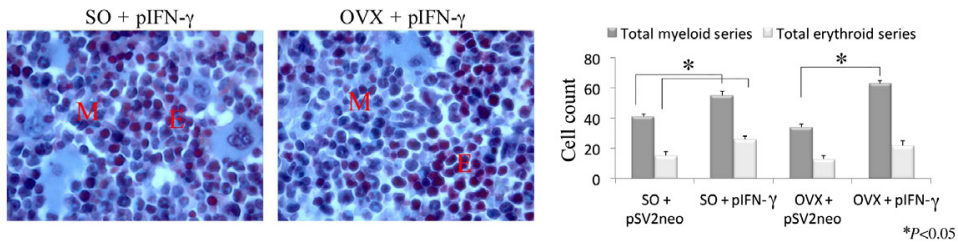

F

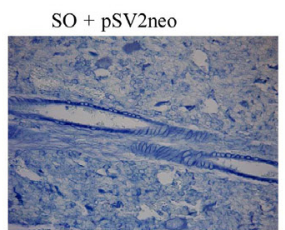

OVX + pSV2neo
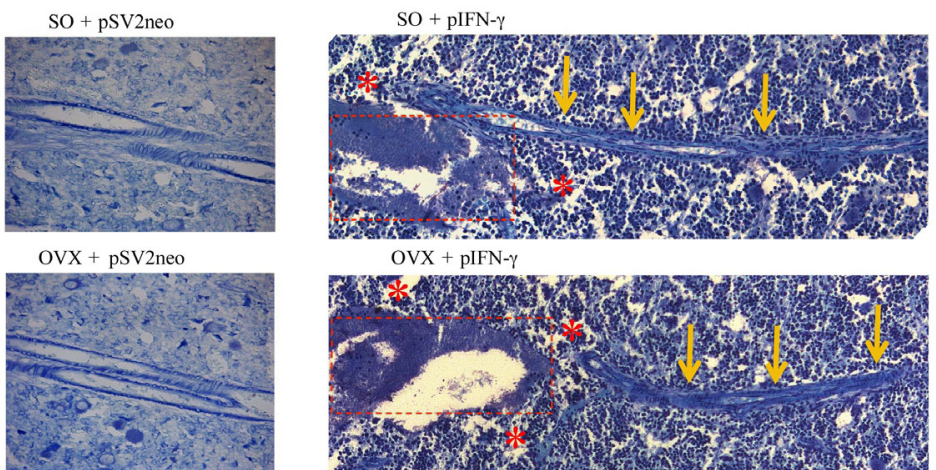

$\mathrm{OVX}+\mathrm{pIFN}-\gamma$

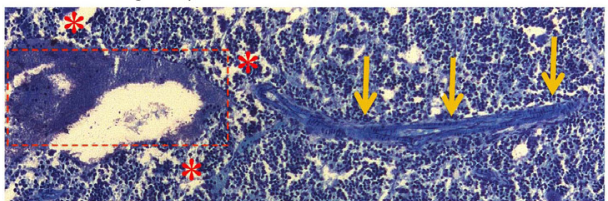

Figure 6

Representative Western blotting of CXCL12 (A) and TGF- $\beta$ (C) of bone marrow stromal cells (BMSCs) from SO and OVX mice treated with pSV2neo or with pINF- $\gamma$ ( $n=6$ mice per group). Localization of CXCL12 at femur sub-metaphyseal areas from mice SO vector treated (Ba), OVX vector treated (Be), SO pINF- $\gamma$-treated (Bc) and OVX pINF- $\gamma$-treated (Bg), analyzed on 12 sections from each sample, by epi-fluorescence microscope using the rabbit anti-CXCL12 antibody (green: FITC staining). Histological sections from the same regions are shown (Bb, Bd, Bf and Bh). (TB: trabecular bone). Magnifications: 20x. Representative images of bone marrow cellularity obtained from longitudinal sections of femurs from mice SO and OVX pSV2neo or pIFN- $\gamma$ treated. Magnification: $20 \times(D)$. Hematopoietic lineages distribution in pIFN- $\gamma$-treated mice groups. Magnification: $100 \times$; statistical analysis of myeloid and erythroid lineages differential count (the count includes cells in late stage of differentiation and differentiated) analyzed on 16 sections from each sample (E); $P<0.05$. Representative images of SO-pSV2neo treated, OVX-pSV2neo treated, SO-pIFN- $\gamma$ treated and OVX-pIFN- $\gamma$ treated. The red cluster indicates the central vein and the arrowheads designate the nutrient arteries. The asterisks denote the venous sinuses (F).

Taking together, these data point on the fact that an increased level of INF- $\gamma$, at least in the bone/bone marrow microenvironment not only aggravates the osteopenic process but also creates favorable conditions for the onset of the pathology.

Another finding from our studies is that pIFN- $\gamma$ negatively affects the bone marrow confines, disturbing bone marrow niche.
Notwithstanding, bone marrow components spatial variations, in some cases, are accompanied by hematopoietic cells alteration (Agas et al. 2015), and estrogen depletion strongly modifies bone marrow homeostasis in rodents (Benayahu et al. 2000, Travlos $2006 a, b)$. In line, we observed that the pIFN- $\gamma$ effects were deleterious for the bone marrow niches mainly within an inflammatory scenario produced by ovariectomy. The

Published by Bioscientifica Ltc. 
presence of hypercellular areas, observed within the bone marrow in pINF- $\gamma$-treated mice, was the case test of these changes. Moreover, in OVX-pIFN- $\gamma$-treated mice group, the myeloid/erythroid (M:E) ratio was found increased, consistently with the observation that the expansion of granulopoietic cells is often associated with the inflammatory response (Travlos 2006a). Further studies are required to determine the number of cells of myeloid and erythroid cells in proliferation and maturation phases after pIFN- $\gamma$ administration.

Reduction of nutrient arteries, venous sinuses and trabecular bone volume usually are accompanied by increasing adipocytes (Burkhardt et al. 1987). In our studies, bone marrow phenotype of pIFN- $\gamma$-treated mice meets the above pathologic postures and, of interest, strongly buttresses the fact that within a chronic inflammatory scenario (OVX mice pIFN- $\gamma$ treatment), M:E ratio and venous/sinusoid morphology are seriously compromised.

IFN- $\gamma$ has also been designated as enhancer of tissue regeneration and differentiation in stem cell transplantation studies and coined as promising inducer of mesenchymal/stromal stem cell differentiation (Duque et al. 2009, Zahir et al. 2009). Bearing in mind that (i) INF- $\gamma$-induced suppression of osteoblast maturation may account for the decreased CXCL12 expression in the bone marrow (present results); (ii) impaired CXCL12 expression by osteoblasts appears to be a common and key step in cytokineinduced HSCs mobilization (Christopher et al. 2009); (iii) compromised TGF- $\beta$ signaling results in impaired MSCs anti-inflammatory response (Singer \& Caplan 2011), our findings indicate the unsuitable role of IFN- $\gamma$ in bone marrow transplantation due to its ability to regulate granulocyte colony-stimulating factor (G-CSF) and CXCL12 signaling.

Collectively, our findings demonstrated for the first time that such a way of IFN- $\gamma$ administration, based on plasmid coding gene, induced bone resorption but, more importantly, markedly affects bone marrow niches. Noteworthy, these harmful effects of pIFN- $\gamma$ should be considered in case of its use as vaccine or vaccine adjuvant, and in other circumstances in which immunostimulation might be required.

\section{Supplementary data}

This is linked to the online version of the paper at http://dx.doi.org/10.1530/ JOE-16-0538.

\section{Declaration of interest}

The authors declare that there is no conflict of interest that could be perceived as prejudicing the impartiality of the research reported.

\section{Funding}

The study was supported by University of Camerino FAR 2014-2015 (grant number BVI000014) and University of Camerino Funds for research (grant number BBI000060).

\section{Acknowledgements}

The authors thank Dr Franco $M$ Venanzi for the critical reading of the manuscript. They also thank S Cammertoni and S Riccioni for the technical assistance.

\section{References}

Agas D, Marchetti L, Capitani M \& Sabbieti MG 2013 The dual face of parathyroid hormone and prostaglandins in the osteoimmune system. American Journal of Physiology: Endocrinology and Metabolism 305 E1185-E1194. (doi:10.1152/ajpendo.00290.2013)

Agas D, Marchetti L, Douni E \& Sabbieti MG 2015 The unbearable lightness of bone marrow homeostasis. Cytokine and Growth Factor Reviews 26 347-359. (doi:10.1016/j.cytogfr.2014.12.004)

Agas D, Concetti F, Capitani M, Lacava G, Concetti A, Marchetti L, Laus F, Marchegiani A, Azevedo V, Sabbieti MG, et al. 2016 Administration of plasmid coding protein aggregating domain induces inflammatory bone loss. Current Gene Therapy 16 144-152. (doi:10.2174/156652321 6666160331125355)

Benayahu D, Shur I \& Ben-Eliyahu S 2000 Hormonal changes affect the bone and bone marrow cells in a rat model. Journal of Cellular Biochemistry 79 407-415. (doi:10.1002/10974644(20001201)79:3<407::AID-JCB60>3.0.CO;2-8)

Bianco P, Cao X, Frenette PS, Mao JJ, Robey PG, Simmons PJ \& Wang CY 2013 The meaning, the sense and the significance: translating the science of mesenchymal stem cells into medicine. Nature Medicine 19 35-42. (doi:10.1038/nm.3028)

Bruemmer D, Collins AR, Noh G, Wang W, Territo M, Arias-Magallona S, Fishbein MC, Blaschke F, Kintscher U, Graf K, et al. 2003 Angiotensin II-accelerated atherosclerosis and aneurysm formation is attenuated in osteopontin-deficient mice. Journal of Clinical Investigation 112 1318-1331. (doi:10.1172/JCI200318141)

Burkhardt R, Kettner G, Böhm W, Schmidmeier M, Schlag R, Frisch B, Mallmann B, Eisenmenger W \& Gilg T 1987 Changes in trabecular bone, hematopoiesis and bone marrow vessels in aplastic anemia, primary osteoporosis, and old age: a comparative histomorphometric study. Bone 8 157-164. (doi:10.1016/8756-3282(87)90015-9)

Christopher MJ, Liu F, Hilton MJ, Long F \& Link DC 2009 Suppression of CXCL12 production by bone marrow osteoblasts is a common and critical pathway for cytokine-induced mobilization. Blood $\mathbf{1 1 4}$ 1331-1339. (doi:10.1182/blood-2008-10-184754)

de Bruin AM, Demirel Ö, Hooibrink B, Brandts CH \& Nolte MA 2013 Interferon- $\gamma$ impairs proliferation of hematopoietic stem cells in mice. Blood 121 3578-3585. (doi:10.1182/blood-2012-05-432906)

Duque G, Huang DC, Macoritto M, Rivas D, Yang XF, Ste-marie LG \& Kremera R 2009 Autocrine regulation of interferon gamma in mesenchymal stem cells plays a role in early osteoblastogenesis. Stem Cells 27 550-558. (doi:10.1634/stemcells.2008-0886) http://joe.endocrinology-journals.org DOI: 10.1530/JOE-16-0538
๑) 2017 Society for Endocrinology Printed in Great Britain 
Duque G, Huang DC, Dion N, Macoritto M, Rivas D, Li W, Yang XF, Li J, Lian J, Marino FT, et al. 2011 Interferon- $\gamma$ plays a role in bone formation in vivo and rescues osteoporosis in ovariectomized mice. Journal of Bone and Mineral Research 26 1472-1483. (doi:10.1002/jbmr.350)

Egan KP, Brennan TA \& Pignolo RJ 2012 Bone histomorphometry using free and commonly available software. Histopathology 61 1168-1173. (doi:10.1111/j.1365-2559.2012.04333.x)

Ehninger A \& Trumpp A 2011 The bone marrow stem cell niche grows up: mesenchymal stem cells and macrophages move in. Journal of Experimental Medicine 208 421-428. (doi:10.1084/jem.20110132)

Ehtesham M, Samoto K, Kabos P, Acosta FL, Gutierrez MA, Black KL \& Yu JS 2002 Treatment of intracranial glioma with in situ interferongamma and tumor necrosis factor-alpha gene transfer. Cancer Gene Therapy 9 925-934. (doi:10.1038/sj.cgt.7700516)

Evans CH 2010 Gene therapy for bone healing. Expert Reviews in Molecular Medicine 12 e18. (doi:10.1017/S1462399410001493)

Fang J, Zhu YY, Smiley E, Bonadio J, Rouleau JP, Goldstein SA, McCauley LK, Davidson BL \& Roessler BJ 1996 Stimulation of new bone formation by direct transfer of osteogenic plasmid genes. PNAS 93 5753-5758. (doi:10.1073/pnas.93.12.5753)

Gao Y, Grassi F, Ryan MR, Terauchi M, Page K, Yang X, Weitzmann MN \& Pacifici R 2007 IFN-gamma stimulates osteoclast formation and bone loss in vivo via antigen-driven T cell activation. Journal of Clinical Investigation 117 122-132. (doi:10.1172/JCI30074)

Gericke A, Qin C, Spevak L, Fujimoto Y, Butler WT, Sorensen ES \& Boskey AL 2005 Importance of phosphorylation for osteopontin regulation of biomineralization. Calcified Tissue International 77 45-54. (doi:10.1007/s00223-004-1288-1)

Harsløf T, Sørensen L, Pedersen S \& Langdahl B 2013 Cytokine levels in the bone marrow are not just a reflection of the levels in serum: suggesting that bone marrow constitutes an independent compartment. Bone Abstracts 1 PP351. (doi:10.1530/boneabs.1.PP351)

Ishii KJ, Weiss WR, Ichino M, Verthelyi D \& Klinman DM 1999 Activity and safety of DNA plasmids encoding IL-4 and IFN gamma. Gene Therapy 6 237-244. (doi:10.1038/sj.gt.3300799)

Jung Y, Wang J, Schneider A, Sun YX, Koh-Paige AJ, Osman NI, McCauley LK \& Taichman RS 2006 Regulation of SDF-1 (CXCL12) production by osteoblasts; a possible mechanism for stem cell homing. Bone $\mathbf{3 8}$ 497-508. (doi:10.1016/j.bone.2005.10.003)

Liu Y, Wang L, Kikuiri T, Akiyama K, Chen C, Xu X, Yang R, Chen W, Wang S \& Shi S 2011 Mesenchymal stem cell-based tissue regeneration is governed by recipient T lymphocytes via IFN- $\gamma$ and TNF- $\alpha$. Nature Medicine 17 1594-1601. (doi:10.1038/nm.2542)

McManus MM \& Grill RJ 2011 Longitudinal evaluation of mouse hind limb bone loss after spinal cord injury using novel in vivo methodology. Journal of Visualized Experiments 758. (doi:10.3791/3246)

Moon YM, Yoon BY, Her YM, Oh HJ, Lee JS, Kim KW, Lee SY, Woo YJ, Park KS, Park SH, et al. 2012 IL-32 and IL-17 interact and have the potential to aggravate osteoclastogenesis in rheumatoid arthritis. Arthritis Research and Therapy 13 R246. (doi:10.1186/ar4089)

Pang M, Martinez AF, Jacobs J, Balkan W \& Troen BR 2005 RANK ligand and interferon gamma differentially regulate cathepsin gene expression in pre-osteoclastic cells. Biochemical and Biophysical Research Communications 328 756-763. (doi:10.1016/j.bbrc.2004.12.005)

Pacifici R 2016 The role of IL-17 and TH17 cells in the bone catabolic activity of PTH. Frontiers in Immunology 7 57. (doi:10.3389/ fimmu.2016.00057)

Reinhardt RL, Liang HE, Bao K, Price AE, Markus Mohrs M, Kelly BL \& Locksley RM 2015 A novel model for IFN- $\gamma$-mediated autoinflammatory syndromes. Journal of Immunology 194 2358-2368. (doi:10.4049/jimmunol.1401992)
Sabbieti MG, Agas D, Marchetti L, Santoni G, Amantini C, Xiao L, Menghi G \& Hurley MM 2010 Signaling pathways implicated in PGF2alpha effects on Fgf2+/+ and Fgf2-/- osteoblasts. Journal of Cellular Physiology 224 465-474. (doi:10.1002/jcp.22143)

Sabbieti MG, Agas D, Capitani M, Marchetti L, Concetti A, Vullo C, Catone G, Gabai V, Shifrin V, Sherman MY, et al. 2015 Plasmid DNAcoding p62 as a bone effective anti-inflammatory/anabolic agent. Oncotarget 6 3590-3599. (doi:10.18632/oncotarget.2884)

Shimizu H, Nakagami H, Yasumasa N, Mariana OK, Kyutoku M, Koriyama H, Nakagami F, Shimamura M, Rakugi H \& Morishita R 2012 Cilnidipine, but not amlodipine, ameliorates osteoporosis in ovariwctomized hypertensive rats through inhibition of the N-type calcium channel. Hypertension Research 35 77-81. (doi:10.1038/hr.2011.143)

Singer NG \& Caplan AI 2011 Mesenchymal stem cells: mechanisms of inflammation. Annual Review of Pathology 6 457-478. (doi:10.1146/ annurev-pathol-011110-130230)

Sugiyama T, Kohara H, Noda M \& Nagasawa T 2006 Maintenance of the hematopoietic stem cell pool by CXCL12-CXCR4 chemokine signaling in bone marrow stromal cell niches. Immunity 25 977-988. (doi:10.1016/j.immuni.2006.10.016)

Takayanagi H, Ogasawara K, Hida S, Chiba T, Murata S, Sato K, Takaoka A, Yokochi T, Oda H, Tanaka K, et al. 2000 T-cellmediated regulation of osteoclastogenesis by signalling crosstalk between RANKL and IFN-gamma. Nature 408 600-605. (doi:10.1038/35046102)

Travlos GS $2006 a$ Normal structure, function, and histology of the bone marrow. Toxicologic Pathology 5 548-565. (doi:10.1080/01926230600939856)

Travlos GS 2006b Histopathology of bone marrow. Toxicologic Pathology 34 566-598. (doi:10.1080/01926230600964706)

Vidal C, Bermeo S, Li W, Huang D, Kremer R \& Duque G 2012 Interferon gamma inhibits adipogenesis in vitro and prevents marrow fat infiltration in oophorectomized mice. Stem Cells 30 1042-1048. (doi:10.1002/stem.1063)

Waung JA, Maynard SA, Gopal S, Gogakos A, Logan JG, Williams GR \& Bassett JH 2014 Quantitative X-ray microradiography for highthroughput phenotyping of osteoarthritis in mice. Osteoarthritis and Cartilage 22 1396-1400. (doi:10.1016/j.joca.2014.04.015)

Weber GF, Zawaideh S, Hikita S, Kumar VA, Cantor H \& Ashkar S 2002 Phosphorylation-dependent interaction of osteopontin with its receptors regulates macrophage migration and activation. Journal of Leukocyte Biology 72 752-776. (doi:10.1038/cr.2014.16)

Weitzmann MN \& Pacifici R 2006 Estrogen deficiency and bone loss: an inflammatory tale. Journal of Clinical Investigation 116 1186-1194. (doi:10.1172/JCI28550)

Xu Z, Hurchla MA, Deng H, Uluçkan O, Bu F, Berdy A, Eagleton MC, Heller EA, Floyd DH, Dirksen WP, et al. 2009 Interferon-gamma targets cancer cells and osteoclasts to prevent tumor-associated bone loss and bone metastases. Journal of Biological Chemistry 284 4658-4666. (doi:10.1074/jbc.M804812200)

Yuan Q, Jiang Y, Zhao X, Sato T, Densmore M, Schüler C, Erben RG, McKee MD \& Lanske B 2014 Increased osteopontin contributes to inhibition of bone mineralization in FGF23-deficient mice. Journal of Bone and Mineral Research 29 693-704. (doi:10.1002/ jbmr.2079)

Zahir T, Chen YF, MacDonald JF, Leipzig N, Tator CH \& Shoichet MS 2009 Neural stem/progenitor cells differentiate in vitro to neurons by the combined action of dibutyryl cAMP and interferon-gamma. Stem Cells and Development 18 1423-1432. (doi:10.1089/scd.2008.0412)

Zhao Z, Wang Z, Ge C, Krebsbach P \& Franceschi RT 2007 Healing cranial defects with AdRunx2-transduced marrow stromal cells. Journal of Dental Research 86 1207-1211. (doi:10.1177/154405910708601213)

Received in final form 20 November 2016

Accepted 29 November 2016

Accepted Preprint published online 1 December 2016 http://joe.endocrinology-journals.org

DOI: $10.1530 / J O E-16-0538$
() 2017 Society for Endocrinology Printed in Great Britain 